\title{
O DESGASTE DE TRABALHADORES DE ENFERMAGEM NO CUIDADO A PACIENTES ONCO-HEMATOLÓGICOS HOSPITALIZADOS*
}

Jaçany Aparecida Borges Prudente', Nádia Chiodelli Salum², Francine Lima Gelbcke², Jorge Lorenzetti ${ }^{3}$, Jordelina Schier ${ }^{2}$

'Enfermeira. Mestre em Enfermagem. Hospital Universitário da Universidade Federal de Santa Catarina. Florianópolis-SC-Brasil. ${ }^{2}$ Enfermeira. Doutora em Filosofia, SaúdeeSociedade. Hospital Universitário da UniversidadeFederal deSanta Catarina. Florianópolis-SC-Brasil. ${ }^{3}$ Enfermeira. Doutora em Filosofia, Saúde e Sociedade. Docente da Universidade Federal de Santa Catarina Florianópolis-SC-Brasil.

RESUMO: Trata-se de pesquisa qualitativa tendo como desenho a Pesquisa Convergente-Assistencial, com objetivo de conhecer o desgaste de trabalhadores de enfermagem no cuidado a pacientes onco-hematológicos hospitalizados. A coleta das informações foi realizada com 29 participantes, através de entrevista e grupos focais, em 2012. A análise foi temática, sustentada pelo estado da arte e marco conceitual. Os resultados mostram a presença marcante do desgaste, decorrente da exposição diária e contínua do trabalhador às cargas de trabalho, tanto de materialidade externa, quanto de materialidade interna, com ênfase para às cargas psíquicas. Conclui-se que o desgaste é inerente ao trabalho, contudo não isolado, sendo que as características pessoais e as opções que o trabalhador faz para sua vida podem influenciá-lo. O desgaste produz efeitos na saúde do trabalhador, na equipe de trabalho, na instituição e no próprio paciente; assim é necessária a utilização de estratégias para minimizá-lo.

DESCRITORES: Enfermagem; Carga de trabalho; Esgotamento profissional.

\section{NURSING STAFF'S STRAIN IN THE CARE FOR ONCO-HEMATOLOGICAL PATIENTS RECEIVING INPATIENT TREATMENT}

\begin{abstract}
This is qualitative research using ConvergentAssistential Research as the design, aiming to investigate the strain of nursing staff in the care for onco-hematological patients receiving inpatient treatment. Data collection was undertaken with 29 participants, through interviews and focus groups, in 2012. The analysis was thematic, supported by the state of the art and conceptual framework. The results show the striking presence of the strain, resulting from the daily and continuous exposure of the worker to the workloads, both of external materiality and internal materiality, with emphasis on the psychological burdens. It is concluded that the strain is inherent to the work, but that it is not isolated, it being the case that the personal characteristics and the choices which the worker makes for her life can influence it. Strain produces effects on the worker's health, on the work team, on the institution and on the patient herself; thus, it is necessary to use strategies in order to minimize it.
\end{abstract}

DESCRIPTORS: Nursing; Workload; Professional exhaustion.

\section{EL DESGASTE DE TRABAJADORES DE ENFERMERÍA EN EL CUIDADO A PACIENTES ONCO-HEMATOLÓGICOS HOSPITALIZADOS}

RESUMEN: Esta es una investigación cualitativa, cuya base es la Investigación Convergente-Asistencial, que tuvo el objetivo de conocer el desgaste de trabajadores de enfermería en el cuidado a pacientes onco-hematológicos hospitalizados. Las informaciones fueron obtenidas con 29 participantes, por medio de entrevista y grupos focales, en 2012. El análisis fue temático, fundamentado por el estado de arte y marco conceptual. Los resultados muestran la presencia distintiva del desgaste, que viene de la exposición diaria y continua del trabajador a las cargas de trabajo, tanto de materialidad externa, cuanto de materialidad interna, con énfasis en las cargas psíquicas. Se concluye que el desgaste es inherente al trabajo, sin embargo no aislado, siendo que las características personales y las opciones que el trabajador hace para su vida pueden influenciarlo. El desgaste produce efectos en la salud del trabajador, en el equipo de trabajo, en la institución y en el propio paciente; así es necesaria la utilización de estrategias para minimizarlo.

DESCRIPTORES: Enfermería; Carga de trabajo; Agotamiento profesional.

\footnotetext{
*Artigo extraído da Dissertação intitulada: O desgaste de trabalhadores de Enfermagem no cuidado a pacientes onco-hematológicos hospitalizados: causas e estratégias de minimização. Universidade Federal de Santa Catarina, 2014.
}

\section{Autor Correspondente:}

Jaçany Aparecida Borges Prudente

Hospital Universitário Polydoro Ernani de São Thiago

Rua Profa . Maria Flora Pausewang, s/n-88036-800-Florianópolis-SC-Brasil

E-mail: jacanyborges@yahoo.com.br
Recebido: $20 / 10 / 2014$ Finalizado: 16/12/2014 


\section{INTRODUÇÃO}

Estudiosos que discutem o trabalho e sua relação com o trabalhador acreditam que o processo de trabalho pode influenciar no desgaste dos trabalhadores ${ }^{(1-5)}$. Todavia, o desgaste não pode ser analisado apenas à luz das condições ambientais e do processo de trabalho no qual está inserido o trabalhador, sendo fundamental adicionar um conceito que melhor explique a origem do desgaste - as cargas de trabalho ${ }^{(1)}$.

Essas cargas estão presentes nos processos de trabalho e "interatuam dinamicamente entre si e com o corpo do trabalhador, gerando processos de adaptação que se traduzem em desgaste" (1:110); são divididas em cargas de materialidade externa e cargas de materialidade interna.

Nesta perspectiva, é possível reconhecer as cargas de materialidade externa no trabalho da enfermagem: físicas - ruídos, calor, frio, umidade, iluminação, ventilação, radiações ionizantes; químicas - produtos manipulados como antibióticos e quimioterápicos, gases, vapores, pós, fumaça, pastas, líquidos (antissépticos, desinfetantes, esterilizantes); biológicas - no contato com parasitas, bactérias, vírus, fungos (provenientes de doenças infectocontagiosas, fluidos e secreções, manipulação de materiais contaminados); mecânicas - dizem respeito aos objetos de trabalho, à tecnologia empregada, às condições de instalação e manutenção dos materiais e equipamentos que podem levar o trabalhador a contusões, fraturas, feridas e outras lesões ${ }^{(4,6)}$.

Já as cargas de materialidade interna encontradas no trabalho da enfermagem são: fisiológicas - decorrentes do esforço visual e físico, posições incômodas e inadequadas, ruptura no ciclo circadiano, sobrecarga de trabalho, realização de horas extras, dupla ou até tripla jornada de trabalho, trabalho em turnos; psíquicas - provenientes do estresse no trabalho, do ritmo e da intensidade empreendidos, de como o trabalho é organizado e dividido, do convívio com a dor, o sofrimento e a morte, da necessidade de capacitações, das relações de poder, dentre outros ${ }^{(4,6)}$.

Neste contexto, o trabalhador de enfermagem está exposto a diversas cargas no exercício da sua função, pois convive diariamente com as especificidades do seu processo de trabalho, as fragilidades da organização, bem como as dificuldades enfrentadas pela profissão ${ }^{(3,7)}$.

Ao cuidar de pacientes onco-hematológicos, o trabalhador de enfermagem soma as cargas normais do processo de trabalho à sobrecarga de trabalho advindo das exigências de cuidados, tanto nas demandas técnico-assistenciais quanto nas demandas de suporte emocional ao paciente, familiares e acompanhantes durante a terapêutica. Além disso, convive ainda com a presença marcante da dor, do sofrimento e da morte dos pacientes com os quais construiu vínculos.

As cargas de trabalho são responsáveis, entre outros, pelo desgaste emocional dos trabalhadores de saúde e enfermagem e a sobrecarga/excesso dessas cargas leva à ocorrência de acidentes e problemas de saúde. Quanto maior a carga, maior será o desgaste e maior será o comprometimento da saúde do trabalhador ${ }^{(3-4,8)}$.

As fragilidades na organização do trabalho e as dificuldades da profissão também conduzem os trabalhadores de enfermagem a cargas que podem refletir em danos à saúde física e mental, decorrentes da falta de materiais, equipamentos e pessoal, baixos salários, falta de reconhecimento, alta complexidade técnica e tecnológica; relações interpessoais complexas, seja com a equipe multiprofissional, pacientes, acompanhantes ou alunos ${ }^{(3-4)}$.

Além de interferir na saúde do trabalhador, o desgaste compromete o seu trabalho, pois afeta o desempenho, reduz a produtividade e fragiliza a realização do cuidado; favorece o absenteísmo, a rotatividade de trabalhadores e os riscos de acidente no trabalho. Sobretudo, o desgaste interfere na coesão da equipe de trabalho, desestabiliza a instituição e onera a sociedade. $\mathrm{O}$ número reduzido de profissionais na assistência é fator determinante para o aumento das cargas fisiológicas e psíquicas dos trabalhadores ${ }^{(8-13)}$.

Contudo, o trabalho também contribui para a saúde dos trabalhadores como fonte de prazer e meio de subsistência. Através dele o indivíduo se constitui como sujeito, afirmando sua identidade e seu desejo de ser reconhecido socialmente. $\mathrm{O}$ trabalho traz realização pessoal e profissional, conforto, estabilidade, segurança, bens materiais e o prazer de cuidar dos seus pacientes ${ }^{(2-3,14-17)}$.

Assim, este estudo tem por objetivo conhecer o desgaste de trabalhadores de enfermagem 
no cuidado a pacientes onco-hematológicos hospitalizados, pois entende-se que esses trabalhadores estão expostos as cargas de trabalho diferenciadas, em função da especificidade do trabalho assistencial.

\section{MÉTODO}

Trata-se de pesquisa qualitativa tendo como desenho a Pesquisa Convergente-Assistencial (PCA) que permite "uma estreita relação com a prática assistencial", visando buscar "alternativas para solucionar ou minimizar problemas, realizar mudanças e introduzir inovações na prática" $^{\prime \prime 18: 28-29)}$.

O estudo foi desenvolvido em um hospital universitário da região sul do Brasil, com 29 trabalhadores de enfermagem que atuam na unidade de internação, responsável pelo atendimento dos pacientes onco-hematológicos. A escolha dos participantes foi intencional, com convite para participação após explicação dos objetivos do estudo. Estabeleceu-se como critério de inclusão ser trabalhador de enfermagem lotado na unidade do estudo e como critério de exclusão estar afastado por licença saúde, maternidade ou férias.

A coleta das informações foi realizada em novembro de 2012, por meio de entrevista semiestruturada e grupos focais. A amostra foi composta por 29 trabalhadores, tendo participado das entrevistas 07 enfermeiros, 17 técnicos de enfermagem, 03 auxiliares de enfermagem e 02 atendentes de enfermagem e nos grupos focais 04 enfermeiros e 04 técnicos de enfermagem. Com a entrevista buscou-se o entendimento dos trabalhadores de enfermagem acerca do desgaste vivenciado no cuidado aos pacientes oncohematológicos hospitalizados. Foram, também, realizados três encontros com a técnica de grupo focal. Os encontros ocorreram fora do horário de trabalho dos participantes, com intervalo de uma semana entre um e outro e duração de aproximadamente três horas cada. Estes possibilitaram a reflexão dos participantes acerca do processo de trabalho na unidade de internação, do desgaste vivenciado, da importância do cuidar de si e na identificação das estratégias utilizadas pelos trabalhadores de enfermagem para minimizar o desgaste no cuidado aos pacientes onco-hematológicos hospitalizados. A coleta das informações foi gravada, transcrita e analisada, preservando sempre o anonimato dos participantes, identificados com a letra " $\mathrm{P}$ ", seguida de um número sequencial à entrevista.

A análise das informações ocorreu simultaneamente à coleta, pois de acordo com a PCA, no momento da coleta o pesquisador já vai organizando as informações obtidas e buscando familiaridades entre elas através do processo de apreensão. Completando a análise, seguiu-se com a fase de interpretação, na qual foram inseridos os processos que deram lógica aos achados da pesquisa. No processo de síntese deu-se a transcrição das falas dos participantes, que foram organizadas por códigos e, em seguida, agrupadas por similaridades, formando categorias; no processo de teorização foram analisadas as categorias seguindo as questões norteadoras do estudo e a análise temática foi sustentada pelo estado da arte e marco conceitual; por fim, no processo de transferência foram divulgados os resultados do estudo.

Os princípios bioéticos foram observados com a submissão do trabalho ao CEPSHUFSC e aprovado sob o protocolo $n^{\circ} 144.444$, obedecendo a Resolução $n^{\circ}$ 196, de 10 de outubro de 1996 que dispõe sobre as Diretrizes e Normas Regulamentadoras de Pesquisa com Seres Humanos, vigente quando da submissão do projeto $^{(19)}$.

\section{RESULTADOS}

Dos 29 participantes, 26 (89,65\%) indicaram a existência de desgaste no cuidado a pacientes onco-hematológicos e 03 (10,35\%) consideraram a inexistência desse desgaste, porém registraram sofrimento nas situações de finitude dos pacientes.

Os aspectos do desgaste apontados pelos participantes foram organizados nas seguintes categorias: O que é desgaste? Existe desgaste no trabalho? Como o desgaste se manifesta? Só o trabalho desgasta? O que move o trabalhador a continuar cuidando?

Na categoria O QUE É DESGASTE? Os trabalhadores o associaram ao cansaço físico, emocional e espiritual; ao estresse contínuo no trabalho ou excesso dele; ao transtorno profissional pela não cura do paciente; ao próprio 
desdobramento para dar conta do trabalho; à exigência de cuidados quando esta ultrapassa os limites de atuação do trabalhador; à pressão extra de quando se leva o trabalho para casa; ao que acontece de forma diversa da planejada.

São ações ou efeitos do trabalho diário, do cotidiano da enfermagem, relacionados a algum dano físico ou emocional, advindo com o estresse do trabalho, muitas vezes repetitivo, longa jornada, duplo vínculo. (P14)

Quanto à categoria EXISTE DESGASTE NO TRABALHO? Dos 29 participantes do estudo, 26 relataram perceber que existe desgaste ao cuidar de pacientes onco-hematológicos.

Tu tens uma preocupação maior com esse tipo de paciente, tu ficas mais envolvida, tanto em termos profissional, como emocional e acaba gastando mais tempo, mais esforço físico, mais esforço emocional; esse paciente depende mais de ti do que os outros. (P06)

O desgaste, também, surgiu relacionado à especificidade do cuidar de pacientes oncohematológicos e em função da patologia acometer pacientes muito jovens.

Eu não conseguia aceitar quando eram uns guris [pacientes] de 17, 18, 19, 20, 25 anos. Ficava imaginando como se fossem meus filhos, e eles ali, sumindo aos pouquinhos. Daímeu Deus, os meus casos de depressão, os maiores, foram por conta deles [...] isso aí acaba com a gente. (P17)

É claro que existe desgaste físico, mas desgaste físico a gente recupera, agora o desgaste emocional nossa, a gente vai para casa e até chora [...]. Já faz 21 anos, mas eu me lembro de cada um, de cada rosto, de cada nome, de cada história de vida e isso não tem noite de sono, não tem férias. A gente só aprende a conviver com isso, porque sabe que é um vai e vem [...] não consigo esquecer, não consigo fazer de conta que é só mais um. Para mim cada sofrimento é único, principalmente quando a gente perde. (P20)

Percebe-se que o desgaste não ocorre apenas pela sobrecarga de trabalho, mas, sobretudo pelo convívio com o sofrimento do outro. O tempo de hospitalização e o ambiente de cuidado influenciam na formação de vínculo, de tal forma que trabalhador e paciente passam a compartilhar o carinho no trato, a confiança nos cuidados e a esperança de cura. Contudo, em função da complexidade da doença, também compartilham insucessos, tristezas e pesares, sendo estes últimos os responsáveis pelo maior desgaste no trabalhador.

Em relação às cargas de trabalho foram identificadas cargas de materialidade externa e interna que afetam no desgaste. Em relação às cargas de materialidade externa, apontam principalmente as cargas químicas e biológicas, identificadas no serviço de enfermagem:

Tem o risco químico e biológico [...] embora eu tente fazer tudo para me cuidar, conforme aprendi nas capacitações, usando EPIs. (P11)

Em relação às cargas de materialidade interna apontam a exposição às cargas psíquicas e fisiológicas, destacando a sobrecarga em atender as demandas do paciente e do processo de trabalho, pois enquanto cuida, emprega as estruturas psicológica e física na assistência ao paciente onco-hematológico. No ato de cuidar do outro, o trabalhador desgasta-se, pois a demanda de trabalho, geralmente, é maior que o tempo e a energia para desenvolvê-lo e o reflexo disso é que o cuidado oferecido nem sempre é o desejado.

Desgaste físico e desgaste emocional, o físico é esse que a gente vive no nosso dia a dia [...] o número muito reduzido de profissionais [...] medicações, sinais vitais, trocas de fralda são duas, três vezes. E o emocional é na questão dessas perdas que nos deixam psicologicamente abalados. (P13)

Mesmo não buscando a prevalência das cargas de trabalho, os participantes destacaram que as cargas psíquicas são as que mais promovem o desgaste no trabalhador de enfermagem que cuida de pacientes onco-hematológicos.

$\mathrm{Na}$ categoria COMO O DESGASTE SE MANIFESTA? Confirmaram que o desgaste pode provocar manifestações físicas e psíquicas, sendo que nas físicas destacam-se o cansaço, a fadiga, as 
dores musculares, lombares, articulares e cefaleias; enquanto nas psíquicas destacam-se as mudanças no humor e comportamento, como irritabilidade, estresse, agonia, depressão, agressividade, revolta, choro, tristeza, carência de apoio, necessidade de conversar ou introspecção. Destacam, ainda, que estas manifestações de desgaste se refletem no trabalho, provocando diminuição de ritmo, indisposição, falta de motivação e de prazer, insatisfação e desesperança.

O desgaste se manifesta quando você começa a ficar irritado por pouca coisa, quando você fica deprimido, entristecido, quando você começa a não querer mais atitudes, comportamento de responsabilidade. Manifesta-se a partir do momento que você não tem mais prazer naquilo que faz. (P02)

Em relação à categoria SÓ O TRABALHO DESGASTA? Reconhecem que o desgaste não é atribuído exclusivamente ao trabalho, mas também as opções que o trabalhador faz para sua vida, como duplo vínculo, problemas particulares e até as características pessoais, podendo aumentá-lo.

Eu acho que é um conjunto de coisas na verdade, tem o desgaste emocional, tem o desgaste físico, mas também as frustrações que a gente carrega, não deixam de ser um desgaste [...]. Esse desgaste vem de casa também, porque não tem como separar por completo, tua casa, teu outro trabalho [...] tem que pesar tudo. (P11)

$\mathrm{Na}$ categoria identificada como "O QUE MOVE O TRABALHADOR A CONTINUAR CUIDANDO?" Destacaram que são movidos por gostarem de cuidar, pois cuidar de pacientes oncohematológicos traz oportunidade de aprendizado, satisfação em ajudar a diminuir o sofrimento, sentimento de realização profissional. Foram destacados como facilitadores no processo de trabalho: o tempo de internação, o envolvimento e coesão da equipe multiprofissional, o aparato tecnológico utilizado, a ampliação da segurança do trabalhador - como a diluição das medicações quimioterápicas em local adequado e a disponibilização de EPIs.

Apesar da gravidade, são pacientes extremamente esclarecidos em relação à doença, são conscientes na interação com a gente, então torna mais fácil o acesso a eles. Essa troca é maior. Eles até te ajudam, olha: hoje eu tenho quimio tal hora, não que a gente dependa disso, mas ele está ligado sempre, e isso é bom, a participação ativa deles. (P13)

Os participantes destacaram, também, que são movidos pelo resultado que o cuidado traz, pois o cuidado melhora o estado do paciente, seja pelo conforto proporcionado, seja pela amenização do sofrimento. Os trabalhadores apresentaram sentimentos distintos, como: empatia, compaixão, preocupação, insegurança, tensão, angústia, impotência. Sobretudo, sentem-se gratificados ao observar melhora no estado clínico do paciente, como uma constatação do dever cumprido e de um trabalho bem executado.

O lado bom de trabalhar com esses pacientes é valorizar a vida [choros e pausa] cada paciente que vai, deixa uma grande mensagem. Eu vejo muito mais que doença, [...] começa a perceber, como são importantes as pequenas coisas da vida [...] aprende a olhar com outro olhar, e isso faz a gente refletir a nossa vida, as nossas ações, os nossos pensamentos. (P02)

As falas mostraram que a busca pela vida, a construção do vínculo e a cura do paciente afetam o trabalhador, promovendo sua reflexão, valorização da vida e superação de obstáculos.

\section{DISCUSSÃO}

O entendimento dos participantes denotou que o desgaste origina-se do excesso de trabalho e do sofrimento dele advindo, repercutindo diretamente na vida e saúde dos trabalhadores. Estes apontamentos corroboram com a percepção de autores, quando discutem o desgaste como:

a perda de capacidade efetiva e/ou potencial, biológica e psíquica. Ou seja, não se refere a algum processo particular isolado, mas sim ao conjunto dos processos biopsíquicos. ${ }^{(1: 15)}$

Neste sentido, o desgaste é multifatorial, ou seja, produzido no trabalho, mas fomentado pelas escolhas de vida do trabalhador e até 
mesmo por características de sua personalidade. Entende-se que o desgaste profissional impacta diretamente na vida e saúde dos trabalhadores; na equipe de enfermagem, com a perda da coesão, fragmentação do espírito de equipe e sobrecarga de trabalho; na instituição, com a dificuldade de garantir uma escala de trabalho dentro da carga horária proposta; e, na sociedade torna-se dispendioso pela necessidade do pagamento de horas extras, contratação de novos trabalhadores, bem como no tratamento de saúde do trabalhador afastado, além de, sobretudo, poder comprometer a realização do cuidado ao paciente.

O desgaste existe e é inerente ao trabalho da enfermagem, entretanto, as demandas técnicoassistenciais (medicamentos, quimioterapias, transfusões, reações adversas, efeitos colaterais, procedimentos, controles, entre outros) dos pacientes onco-hematológicos têm contribuído para o aumento do desgaste tanto físico quanto emocional dos seus trabalhadores. Somam-se a estes aspectos a demanda emocional do paciente e de seus familiares gerada pela gravidade da doença e imprevisibilidade da terapêutica.

Dentre as profissões envolvidas diretamente com a assistência a saúde, a enfermagem é apontada como a que apresenta os maiores índices de exaustão emocional, despersonalização e baixo nível de realização profissional, ou seja, risco acentuado de desenvolvimento do Burnout nos seus trabalhadores ${ }^{(20)}$.

Os relatos dos participantes denotam uma compreensão de que o desgaste está presente no trabalho, que convivem com ele e percebem ainda que pode levá-lo ao adoecimento, além de prejudicar a equipe de trabalho e fragilizar o cuidado realizado aos pacientes. Assim, o desgaste é um problema também institucional que precisa ser considerado e amenizado por meio de estratégias que promovam a saúde dos seus trabalhadores.

Essas estratégias precisam, sobretudo melhorar as condições de trabalho, adequar o dimensionamento de pessoal, diminuir a sobrecarga e jornada de trabalho, além de incentivar e investir na qualificação do trabalhador ${ }^{(13)}$.

Os trabalhadores identificam no processo de trabalho cargas de materialidade externa, relacionadas principalmente aos agentes biológicos em função da mudança do perfil das infecções, com aumento significativo das bactérias multirresistentes entre os pacientes hospitalizados, bem como das doenças infectocontagiosas e as cargas químicas, em função das quimioterapias e das diversas medicações necessárias ao tratamento do câncer.

Quanto à identificação das cargas de materialidade interna, as cargas psíquicas são predominantes, e interferem no adoecimento do trabalhador, trazendo-lhe marcas de difícil identificação(4) ${ }^{(4)}$ Jas cargas fisiológicas são mais fáceis de superar com descanso e folgas.

O trabalho é determinante na saúde dos trabalhadores, influenciado naturalmente pelas condições e ambiente. Além disso, a doença tem correlação com variáveis pessoais e institucionais e alguns trabalhadores podem adoecer, dependendo de como reagem e respondem às eventualidades do trabalho ${ }^{(2,21)}$.

Enfim, o desgaste pode apresentar diversas manifestações nos trabalhadores, de ordem física e psicológica, com reflexo direto na vida pessoal e profissional, fragilizando-os sobremaneira. É essencial um envolvimento dos trabalhadores no que se refere à priorização da sua saúde, como forma de minimizar o desgaste profissional e para tanto o trabalhador precisa apropriar-se de estratégias que possam minimizar o desgaste que é próprio do trabalho. O problema está quando esses trabalhadores possuem outro vínculo empregatício e outras atividades estressantes, com pouca ou nenhuma estratégia que minimizem o desgaste. A manutenção da saúde do trabalhador depende desse equilíbrio e, para tanto, precisa de tempo, foco e determinação: tempo para cuidarse, foco para finalizar o provisório e determinação para viver bem e com qualidade.

Os baixos salários e a jornada dupla ou tripla de trabalho fazem parte de um conjunto de fatores que expõe o trabalhador à precarização das condições de trabalho, levam ao cansaço excessivo, além de aumentar a probabilidade de negligenciar condutas que podem comprometer a realização do cuidado e subtrair o tempo livre do trabalhador, dificultando principalmente o convívio familiar e o lazer - que são estratégias que minimizam o desgaste do trabalho ${ }^{(22)}$.

Acredita-se que alguns problemas no atendimento de saúde no mundo são por falhas no formato do sistema que permite carga horária 
excessiva de trabalho. Essas falhas reduzem comprovadamentea segurança do paciente e o bem estar dos trabalhadores, comprometendo assim a assistência em saúde e a saúde do trabalhador ${ }^{(23)}$.

Há que se destacar, ainda, que o tratamento de uma doença onco-hematológica é complexo, específico e especializado, envolvendo um aparato científico, tecnológico e multiprofissional. É um processo de trabalho dinâmico, no qual interagem diversos profissionais, uma vez que a terapêutica é cercada de riscos, instabilidades e incertezas, além de requerer competência, comprometimento e dedicação do trabalhador, a fim de corresponder às demandas do cuidado. As questões éticas e o compromisso profissional com o outro em situação de vulnerabilidade, constituiu-se em importante aspecto de reflexão dos participantes deste estudo no sentido de serem empáticos diante dos desafios diários impostos pela doença e tratamento oncohematológico, apontando que o fato de atuarem junto a estes pacientes traz satisfação no trabalho.

Observa-se que enquanto cuida, o trabalhador pode refletir e crescer a partir das experiências do outro, utilizando as ferramentas que lhe são oportunizadas e isso é um privilégio da enfermagem. Estudo realizado com trabalhadores de enfermagem mostrou que a satisfação do trabalhador com o seu trabalho é materializada na visualização da melhora do paciente e ao perceber-se como sujeito no seu processo de trabalho. Também, quando tem autonomia no trabalho há diminuição do desgaste psicológico ${ }^{(2-3)}$.

O trabalhador de enfermagem vivencia sentimentos de prazer e de sofrimento no seu trabalho. Neste sentido, reconhece-se que o trabalho pode ser fonte de sofrimento, desgaste e adoecimento, contudo o trabalho também pode ser fonte de prazer, realização profissional e satisfação pessoal. Assim, é essencial ao trabalhador compreender as peculiaridades da profissão, gostar do trabalho que exerce e, sobretudo, apropriar-se de estratégias que possam minimizar o desgaste profissional como forma de preservar sua vida, saúde e profissão.

Desta forma, é fundamental identificar os fatores causadores de prazer e sofrimento no trabalho como forma de promover a saúde, prevenir o adoecimento físico e psíquico dos trabalhadores, bem como tornar o ofício uma atividade prazerosa ${ }^{(14,16)}$.

\section{CONSIDERAÇÕES FINAIS}

Ao cuidar de pacientes onco-hematológicos, o trabalhador de enfermagem está exposto a diversas cargas de trabalho, tanto de materialidade externa, quanto de materialidade interna, com ênfase para a exposição às cargas psíquicas. A exposição diária e contínua às cargas de trabalho culmina na produção e aumento do desgaste que pode evoluir para o adoecimento do trabalhador. É possível perceber um padrão de desgaste diferenciado entre os trabalhadores de enfermagem, sendo que para alguns se apresenta mais acentuado do que em outros e, quando acentuado, afeta a vida, a saúde e o trabalho dos mesmos. O estudo mostra, sobretudo, que a despeito de todo desgaste profissional vivenciado, os trabalhadores cuidam dos pacientes oncohematológicos porque gostam e porque são movidos pela contribuição que podem oferecer para minimizar seu sofrimento.

Apesar de o desgaste ser inerente ao processo de trabalho, não pode ser considerado de forma isolada, mas sim num contexto, pois é produzido no trabalho, mas as características pessoais e, sobretudo, as opções que o trabalhador faz para sua vida, também, podem influenciar no desgaste profissional. Assim, o desgaste é multifatorial e produz um ciclo vicioso de efeitos no ambiente de trabalho, com repercussão direta na saúde do trabalhador, na equipe de trabalho, na instituição, no próprio trabalho, e consequentemente, no paciente a ser assistido. Enfim, o desgaste tornase um problema social.

Esse ciclo precisa ser rompido, as causas do desgaste no trabalho precisam ser identificadas, amenizadas e/ou eliminadas o mais precocemente possível, através de estratégias institucionais que promovam a saúde do trabalhador. $\mathrm{E}$, acima de tudo, o trabalhador de enfermagem precisa utilizar estratégias individuais que minimizem o desgaste profissional, bem como se apropriar das políticas públicas que podem e devem interferir nas políticas institucionais, a fim de transformar o seu espaço de trabalho, salvaguardando a sua saúde e da equipe, suscitando mudanças na forma como o trabalho é desenvolvido.

Ambientes de prática favoráveis no sentido de gestão compartilhada, condições estruturais adequadas e recursos humanos e materiais suficientes são pré condições para cuidados 
seguros e de qualidade aos pacientes, satisfação e sanidade dos trabalhadores. Neste sentido, a enfermagem deve ter na sua agenda profissional prioritária a construção destes ambientes de prática favoráveis.

\section{REFERÊNCIAS}

1. Laurell AC, Noriega M. Processo de produção e saúde: trabalho e desgaste operário. São Paulo: Hucitec; 1989.

2. Morin E. Sens du travail, santé mentale et engagement organisationnel. [Internet]. IRSST. Quebec, 2008 [acesso em: $10 \mathrm{dez}$ 2010]. Disponível: http://www. irsst.qc.ca/media/documents/PubIRSST/R-543.pdf

3. Azambuja EP, Pires DEP, Vaz MRC, Marziale MH. É possível produzir saúde no trabalho da enfermagem? Texto Contexto enferm. [Internet] 2010;19(8) [acesso em 05 out 2013]. Disponível: http://dx.doi.org/10.1590/ S0104-07072010000400008

4. Secco IAO, Robazzi MLCC, Souza FEA, Shimizu DS. Cargas psíquicas de trabalho e desgaste dos trabalhadores de enfermagem de hospital de ensino do Paraná, Brasil. SMAD [Internet] 2010; 6(1) [acesso em 12 abr 2013]. Disponível: http://www.revistas.usp. $\mathrm{br} / \mathrm{smad} /$ index

5. Ferreira MM, Ferreira C. Carga mental e carga psíquica em profissionais de enfermagem. Revista Portuguesa de Enfermagem de Saúde Mental [Internet] 2014; [acesso em 04 ago 2014]. Disponível: http://www.scielo.gpeari. mctes.pt/scielo.php?script=sci_arttext \&pid=S164721602014000100008\&lng=pt

6. Kirchhof ALC, Lacerda MR, Sarquis LMM, Magnago TSB, Gomes IM. Compreendendo cargas de trabalho na pesquisa em saúde ocupacional na enfermagem. Colomb. Med. [Internet] 2011;42(2 Supl 1) [acesso em 06 nov 2012]. Disponível: http://www.bioline.org.br/ pdf?rc11047

7. Kovács MJ. Sofrimento da equipe de saúde no contexto hospitalar: cuidando do cuidador profissional. O Mundo da Saúde [Internet] 2010; 34(4) [acesso em 06 dez 2012]. Disponível: http://www.saocamilo-sp. br/pdf/mundo_saude/79/420.pdf

8. Santana LL, Miranda FMD, Karino ME, Baptista PCP, Felli VEA, Sarquis LMM. Cargas e desgastes de trabalho vivenciados entre trabalhadores de saúde em um hospital de ensino. Rev. Gauch. enferm. [Internet] 2013;34(1) [acesso em 15 dez 2013]. Disponível: http:// dx.doi.org/10.1590/S1983-14472013000100008

9. Magnabosco G, Goulart CB, Haddad MCL, Vannuchi MTO, Dalmas JC. Síndrome de Burnout em trabalhadores de um hospital público de média
complexidade.Reme, Rev. Min. Enferm. [Internet] 2009;13(4) [acesso em 02 mar 2013]. Disponível: http:// www.reme.org.br/artigo/detalhes/218

10. Belancieri MF, Beluci ML, Silva DVR, Gasparelo EA. A resiliência em trabalhadores da área da enfermagem. Estud. Psicol. [Internet] 2010; 27(2) [acesso em $10 \mathrm{dez}$ 2010]. Disponível: http://dx.doi.org/10.1590/S0103166X2010000200010

11. Beserra FM, Souza AMA, Moreira DA, Alves MDS, D'Alencar BP. Significado do trabalho dos profissionais de enfermagem no hospital geral. Av. enferm. [Internet] 2010; 28(2) [acesso em 18 fev 2013]. Disponível: http://www.scielo.org.co/scielo.php?script=sci_ arttext\&pid=S0121-45002010000200003\&lng=en

12. Oliveira V, Pereira T. Ansiedade, depressão e Burnout em enfermeiros: Impacto do trabalho por turnos. Rev. Enf. Ref. [Internet] 2012; serlII(7) [acesso em 13 ago 2013]. Disponível: http://dx.doi.org/10.12707/RIII1175

13. Trindade LL, Pires DEP, Amestoy SC, Forte ECN, Machado FL, Bordignon M. Trabalho na estratégia da saúde da família: implicações nas cargas de trabalho de seus profissionais. Cogitare enferm. [internet] 2014; 19(3) [acesso em 01 out2014]. Disponível: http://dx.doi. org/10.5380/ce.v19i3.35492

14. Martins JT, Robazzi MLCC, Borbroff MCC. Prazer e sofrimento no trabalho da equipe de enfermagem: reflexão à luz da psicodinâmica. Dejouriana. Rev. Esc. Enferm. USP. [Internet] 2010;44(4) [acesso em $11 \mathrm{dez}$ 2013]. Disponível: http://dx.doi.org/10.1590/S008062342010000400036

15. Traesel ES, Merlo ÁRC. Trabalho imaterial no contexto da enfermagem hospitalar: vivências coletivas dos trabalhadores na perspectiva da Psicodinâmica do Trabalho. Rev. bras. saude ocup. [Internet] 2011; 36(123) [acesso em 19 dez 2013]. Disponível: http:// dx.doi.org/10.1590/S0303-76572011000100005

16. Kessler AI, Krug SBF. Do prazer ao sofrimento no trabalho da enfermagem: o discurso dos trabalhadores. Rev. gauch. enferm. [Internet] 2012; 33(1): 49-55 [acesso em 28 ago 2013]. Disponível: http://dx.doi. org/10.1590/S1983-14472012000100007

17. Santos JLG, Prochnow AG, Silva DC, Silva RM, Leite JL, Erdmann AL. Prazer e sofrimento no exercício gerencial do enfermeiro no contexto hospitalar. Esc. Anna Nery. [Internet] 2013; 17(1) [acesso em $11 \mathrm{fev}$ 2013]. Disponível: http://dx.doi.org/10.1590/S141481452013000100014

18. Trentini M, Paim L. Pesquisa convergente-assistencial: um desenho que une o fazer e o pensar na prática assistencial em saúde-enfermagem. $2^{\mathrm{a}}$ ed. Florianópolis: Insular; 2004.

19. Ministério da Saúde (BR). Conselho Nacional de 
Saúde. Diretrizes e normas regulamentadoras de pesquisa envolvendo seres humanos. Resolução n. 196, [Internet] 10 de outubro [acesso em 22 fev 2012]. Disponível: conselho.saude.gov.br/resolucoes/1996/ reso196.doc

20. Ezaias G, Gouvea PB, Haddad MCL, Vannuchi MTO, Sardinha DSS. Síndrome de Burnout em trabalhadores de saúde em um hospital de média complexidade. Rev. enferm. UER] [Internet] 2010; 2(4) [acesso em 17 ago 2013]. Disponível: http://www.facenf.uerj.br/v18n4/ v18n4a04.pdf

21. Teixeira RC, Mantovani MF. Enfermeiros com doença crônica: as relações com o adoecimento, a prevenção e o processo de trabalho. Rev. Esc. Enferm. USP [Internet] 2009; 43(2) [acesso em 16 jun 2012]. Disponível: http://dx.doi.org/10.1590/S008062342009000200022

22. Prestes FC, Beck CLC, Silva RM, Tavares JP, Camponogara S, Burg G. Prazer-sofrimento dos trabalhadores de enfermagem de um serviço de hemodiálise. Rev. gauch. enferm. [Internet] 2010; 31(4) [acesso em 15 fev 2013]. Disponível: http://dx.doi. org/10.1590/S1983-14472010000400018

23. Landrigan CP. Condições de trabalho e bem-estar dos profissionais de saúde: compartilhamento de lições internacionais para melhorar a segurança do paciente. J. Pediatr. [Internet] 2011; 87(6) [acesso em 10 jun 2013]. Disponível: http://dx.doi.org/10.1590/ S0021-75572011000600001 